\title{
A Study on Positive Photosensitive Epoxy Resins Using Reaction Development Patterning (RDP)
}

\author{
Wei Min Zhou ${ }^{1}$, Takafumi Fukushima ${ }^{2}$, Masao Tomoi ${ }^{3}$, and Toshiyuki Oyama ${ }^{3 *}$ \\ ${ }^{I}$ Research Center of Coal Chemical Engineering and Technology, University of Science and Technology \\ Liaoning, AnShan114051, China \\ ${ }^{2}$ New Industry Creation Hatchery Center (NICHe), Tohoku University \\ 6-6-10 Aza-Aoba, Aramaki, Aoba-ku, Sendai 980-8579, Japan \\ ${ }^{3}$ Department of Advanced Materials Chemistry, Yokohama National University \\ 79-5 Tokiwadai, Hodogaya-ku, Yokohama 240-8501, Japan \\ *oyama1@ynu.ac.jp
}

\begin{abstract}
In this study, we successfully fabricated positive photosensitive epoxy resins based on the Reaction Development Patterning (RDP) by using B-staged polymers prepared by polyaddition between an epoxy base resin and an acid anhydride curing agent during mixing and prebaking processes. Application of RDP to the B-staged polymers afforded positive fine patterns by the use of 15 -mol\% sodium 2-aminoethoxide in ethanolamine / NMP mixtures. Furthermore, the fine epoxy patterns were not deformed after heat treatment for complete curing, indicating that the cress-linked epoxy patterns have high tolerability to thermal stresses. These results suggest the possibility of practical application of RDP-based positive photosensitive epoxy resins.
\end{abstract}

Keywords: photosensitive epoxy resin, reaction development patterning, RDP, positive patterns

\section{Introduction}

In the past several decades, photoresists have been widely applied in the fields of large-scale integration (LSI) and printed circuit boards (PCBs) for the formation of fine line-and-space $(\mathrm{L} / \mathrm{S})$ and dot patterns. The photoresists have been generally prepared by introducing chromophore units in main chains, on side chains, and/or at the chain ends of polymers. Positive and negative patterns are formed in photolithographic processes using solubility differences of the photoresists to developers between UV exposed and unexposed areas [1-8]. In contrast, Fukushima et al. have proposed a new RDP (Reaction Development Pattering) method to easily obtain fine patterns from non-photosensitive plastics such as polyimides, polycarbonates and vinyl polymers that have no chromophore units [9a]. In the RDP, photosensitive additives induce higher permeability of the developers into UV exposed areas than unexposed areas, leading to the selective reactions of main-chain scissions in the exposed areas [9]. This RDP method has a great advantage of high design flexibility in chemical structures of photoresists.

In general, epoxy resins have excellent thermal and mechanical properties and good electrical insulation, and on the basis of these properties, epoxy resins have been widely used in microelectronic packaging such as under filling and molding. Standard epoxy resins are cured by polyaddition of epoxies with hardeners and accelerators [10]. Photosensitive epoxy resins have been reported to form negative-tone fine patterns, for instance, SU- $8^{\circledR}$ for MEMS and solder resist for PCB applications [11]. However, positive-tone fine patterns have never obtained from epoxy resins because patterns of epoxies are obtained as a result of insolubilization at photo-irradiated areas induced by photo-initiated cross-linking of the epoxies. In this paper, we prepare positive patterns of standard bisphenol-A-type epoxy resin without chromophore units by application of the RDP method, and investigate the appropriate pattern forming conditions for the RDP of epoxy resins. 


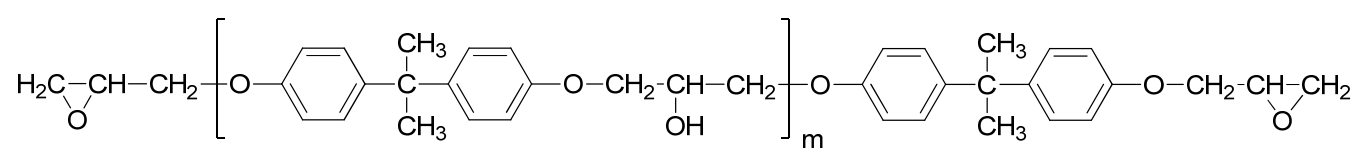

Epikote $828 \quad \begin{aligned} & m=0(86 \%) \\ & m=1(14 \%)\end{aligned}$<smiles>CCCC1C(=O)OC(=O)C1CC</smiles>

MHHPA<smiles>CN(C)Cc1ccccc1</smiles>

BDMA

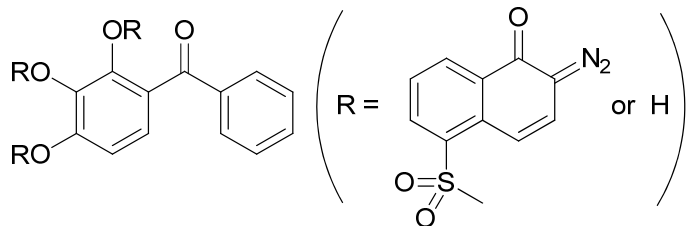

NT-200<smiles>CN1CCCC1=O</smiles>

NMP

Fig. 1 Components of positive photosensitive epoxy resins based on RDP.

\section{Experimental}

\section{1. Materials}

Bisphenol A epoxy resin (Epikote 828) was purchased from Mitsubishi Chemical Co. MHHPA (methylhexahydrophthalic anhydride) was purchased from DIC Corporation. BDMA ( $N$-benzyldimethylamine), 2-aminoethanol and sodium were purchased from Wako Pure Chemical Industries, Ltd. Diazonaphthoquinone (DNQ) compound NT-200 ${ }^{\circledR}$ as a photosensitive additive was purchased from Toyo Gosei, Co. Ltd. N,N-Dimethylformamide (DMF) and $N$-methylpyrrolidone (NMP) were purchased from commercial sources.

\subsection{Measurement}

Molecular weight of the epoxy resins was determined on a TOSOH GPC8020 gel permeation chromatography (GPC) system. The instrument conditions were as follows: elution solvent, $\mathrm{DMF}$ containing $\mathrm{LiBr}$ (30 $\mathrm{mmol} / \mathrm{L})$ and phosphoric acid $(60 \mathrm{mmol} / \mathrm{L})$; gel column, TSK-GEL H-type; flow rate, $0.8 \mathrm{~mL} / \mathrm{min}$ at room temperature. Polystyrene was used as calibrating standard. Scanning electron micrograph (SEM) was taken with a JEOL JSM-6390LV instrument. Photo-irradiation was conducted by a UV exposure apparatus equipped with an ultra high-pressure mercury lamp (ORC, JP-2000-EXC), and exposure dose was measured with wavelengths ranging from 320 to $390 \mathrm{~nm}$ (ORC, UV-331AP2).

\section{Results and Discussion}

Fig. 1 lists the components of positive photosensitive epoxy resins used in this study, and Table 1 depicts preparation conditions of positive photosensitive epoxy solutions and films. As shown in Table 1, the mixing ratios by weight between Epikote 828 and MHHPA were determined as $1 / 0.88$ and $1 / 0.83$.

Contrary to our previous RDP works, we prepare photosensitive films via two stages: mixing and prebaking processes. As shown in Fig. 2a, the polyaddition was carried out at $80{ }^{\circ} \mathrm{C}$ by mixing, which were completed prior to gelation of the epoxy components. The mixing times were $215 \mathrm{~min}$ and 185 min for epoxy/MHHPA of $1 / 0.88$ and $1 / 0.83$, respectively. The resulting molecular weights were $M_{\mathrm{n}} 3,300$ and $M_{\mathrm{w}}$ 66,000 in both the components, as shown in Table 1. NMP solution of $37-w t^{\%} \%$ NT- $200^{\circledR}$ was added into the epoxy components after pre-polymerization in order to a)

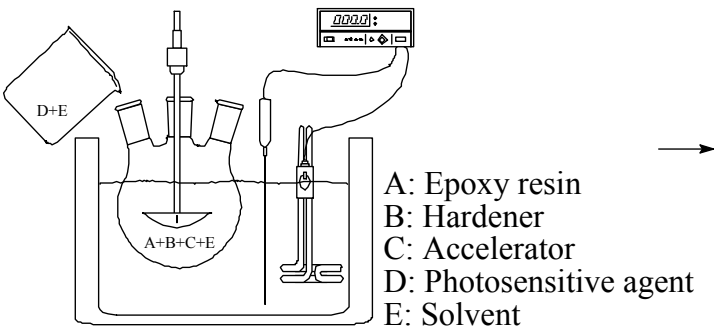

b)

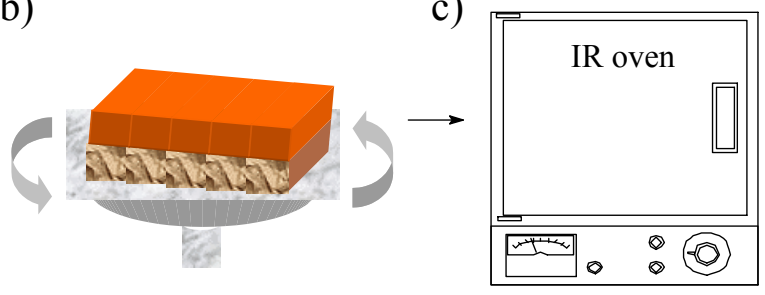

Fig. 2 A process flow of the preparation of positive photosensitive epoxy films.

a) Pre-polymerization of epoxy resin by heating $\mathrm{A}, \mathrm{B}$ and $\mathrm{C}$ in $\mathrm{E}$ and the following addition of $\mathrm{D}$ in $\mathrm{E}$.

b) Spin-coating of the epoxy solutions

c) Prebaking the films in an IR oven to obtain B-staged polymers. 
Table 1 Preparation conditions of two positive photosensitive epoxy solutions and films.

\begin{tabular}{|c|c|c|c|}
\hline & Photosensitive Film & $\alpha$ & $\boldsymbol{\beta}$ \\
\hline \multirow{6}{*}{$\begin{array}{c}\text { Pre-polymeriza- } \\
\text { tion Process }\end{array}$} & $\begin{array}{c}\text { Epoxy/MHHPA } \\
(\mathrm{g} / \mathrm{g})\end{array}$ & $1 / 0.88$ & $1 / 0.83$ \\
\hline & $\operatorname{NMP}(g)$ & 10.6 & 10.6 \\
\hline & BDMA(phr) & 5.0 & 5.0 \\
\hline & Mixing Time (min) & 215 & 185 \\
\hline & $M_{n}$ & 3,300 & 3.300 \\
\hline & $M_{w}$ & 66,000 & 66,000 \\
\hline \multirow{6}{*}{$\begin{array}{c}\text { Prebaking } \\
\text { Process }\end{array}$} & $\mathrm{NT}-200^{\circledR}(\mathrm{g})$ & 2.0 & 2.0 \\
\hline & $\operatorname{NMP}(g)$ & 5.4 & 5.4 \\
\hline & $\begin{array}{l}\text { Prebaking Time } \\
\text { (min) }\end{array}$ & $3,5,25$ & $3,5,25$ \\
\hline & Film Thickness $(\mu \mathrm{m})$ & 17.5 & 17.0 \\
\hline & $M_{n}$ & \multirow{2}{*}{\multicolumn{2}{|c|}{$\begin{array}{l}\text { Not Dissolved in } \\
\text { DMF }\end{array}$}} \\
\hline & $M_{w}$ & & \\
\hline
\end{tabular}

prevent the photosensitive additive from thermally decomposing. The obtained photosensitive polymeric solutions were sufficiently stirred at room temperature.

The photosensitive solutions containing the prepolymerized epoxies and NT-200 ${ }^{\circledR}$ were dropped and spin-coated on copper foils to give photosensitive films, as shown in Fig. 2b. The film thicknesses were controlled in the range of 17-17.5 $\mu \mathrm{m}$ (Table 1). Then, the obtained photosensitive films were treated by the subsequent prebaking process at $90{ }^{\circ} \mathrm{C}$ for 3,5 and $25 \mathrm{~min}$, as shown in Fig. 2c. The molecular weight of the resulting films could not be evaluated by GPC because these films were insoluble in the solvent for GPC measurement due to poor solubility into the eluent solvent (DMF). The films were then exposed with an ultra-high pressure mercury vapor lamp with an exposure dose of $2000 \mathrm{~mJ} / \mathrm{cm}^{2}$ through a photo-mask. The appropriate development conditions for these exposed photosensitive films were examined by controlling the prebaking time, developer components and development time.

In the developing process, similar to our previous studies, we firstly used the mixtures of ethanolamine / $\mathrm{NMP} / \mathrm{H}_{2} \mathrm{O}$ with different weight composition ratios as developers. However, we could not obtain clear patterns of the epoxy resins from these developers. Recently, Oyama et al. have provided a novel developer consisting of sodium alkoxide of ethanolamine, and successfully formed fine patterns of vinyl polymers with maleimide functional groups [9h]. Considering crosslinking of epoxy resins, we also employed the developer using this alkoxide together with NMP to investigate the optimal conditions to form epoxy fine patterns. As a result, when the prebaking times for film preparation were 3 and 5 minutes, we could not obtain clear patterns after the development process using the developers composed of 15 -mol\% sodium 2-aminoethoxide in ethanolamine / NMP with varying ratios. However, as shown in Fig. 3a, the fine patterns were successfully formed from the 25-min prebaked film $\boldsymbol{\alpha}$ by using the developer of 15 -mol\% sodium 2-aminoethoxide in ethanolamine / $\mathrm{NMP}=10 / 1(\mathrm{w} / \mathrm{w})$ for $4 \mathrm{~min} 51 \mathrm{sec}$ of development time. On the other hand, fine patterns were not formed
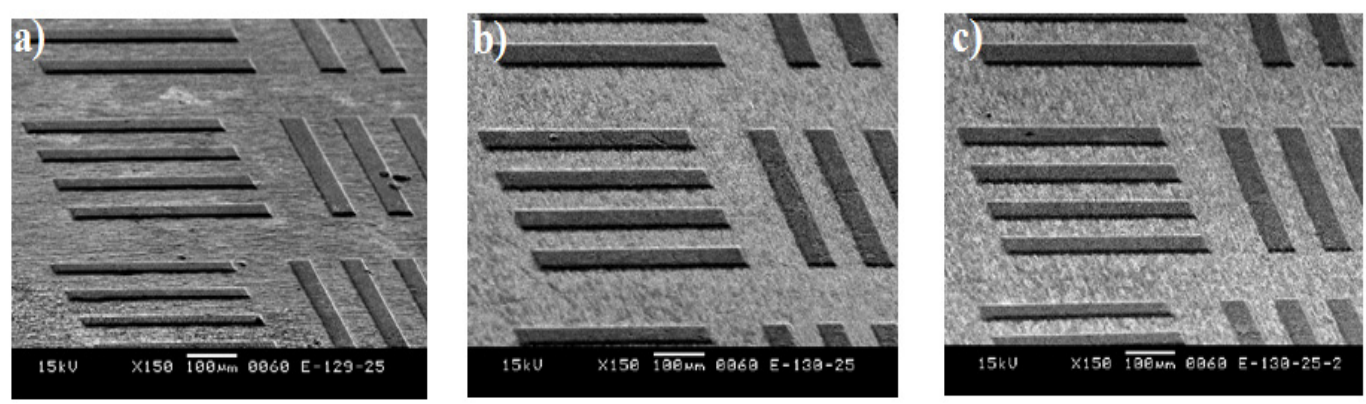

Fig. 3 SEM images of positive epoxy resin patterns $(60 \mu \mathrm{m} \mathrm{L} / \mathrm{S})$.

a) 25 -min prebaked $\boldsymbol{\alpha}$ film developed in developer of 15 -mol $\%$ sodium 2 -aminoethoxide in ethanolamine / NMP = $10 / 1(\mathrm{w} / \mathrm{w})$ with developing time of $4 \mathrm{~min} 51 \mathrm{sec}$ under ultra-sonic treatment.

b) 25 -min prebaked $\boldsymbol{\beta}$ film developed in developer of $15-\mathrm{mol} \%$ sodium 2 -aminoethoxide in ethanolamine / NMP $=$ $23 / 1(\mathrm{w} / \mathrm{w})$ with developing time of $5 \mathrm{~min} 31 \mathrm{sec}$ under ultra-sonic treatment.

c) The patterns resulting from $\boldsymbol{\beta}$ after heating under $100^{\circ} \mathrm{C} / 30 \mathrm{~min}$ and $120^{\circ} \mathrm{C} / 30 \mathrm{~min}$. 
from the 25-min prebaked film $\boldsymbol{\beta}$ in the same developer (15-mol\% sodium 2-aminoethoxide in ethanolamine / NMP $=10 / 1)$. Therefore, we increased the ratio of $15-$ mol $\%$ sodium alkoxide in the developer, and as a result, we succeeded in formation of fine patterns from the 25-min prebaked film $\boldsymbol{\beta}$ with a development time of 5 $\min 31 \mathrm{sec}$ in the developer with $15-\mathrm{mol} \%$ sodium 2-aminoethoxide in ethanolamine / NMP $=23 / 1(\mathrm{w} / \mathrm{w})$ (Fig. 3b). These development results indicate that the film $\boldsymbol{\beta}$ has relatively strong cross-linking networks.

Fig. 4 shows that the mechanisms of polymerization of the epoxy resins and pattern formation of the positive photosensitive epoxy resins. In the pre-polymerization and prebaking steps, BDMA reacts with MHHPA, and the resulting carboxylate anion attacks to an epoxide group of Epikote 828 to give an alkoxide. This alkoxide reacts again with MHHPA, and repetition of these reactions leads to the formation of a B-staged epoxy polymers. In the following irradiation and development steps, the DNQ-containing films are exposed by UV light with an exposure dose of $2000 \mathrm{~mJ} / \mathrm{cm}^{2}$, and the DNQ of
NT-200 ${ }^{\circledR}$ in the exposed areas is rearranged to the indenecarboxylic acid. The indenecarboxylic acid is then reacted with sodium alkoxide in the developer to form a salt, and this salt enhances permeability of the developer into the exposed areas. Nucleophilic reaction between the alkoxide anions in the permeated developer and the ester groups in the B-staged epoxies leads to scission of the ester groups in the polymers at the exposed areas, and dissolution of the decomposed epoxy polymers into the developer resulted in the formation of positive-tone fine patterns as shown in Figs. 3a and 3b.

The fine patterns obtained by RDP were heated at $100^{\circ} \mathrm{C}$ for $30 \mathrm{~min}$ and $120^{\circ} \mathrm{C}$ for $30 \mathrm{~min}$ in order to complete crosslinking of the epoxy resins. As a result, as shown in Fig. 3c, no deformation of the fine patterns was observed after the heat treatment. This indicates that the sufficiently cress-linked epoxy patterns have high tolerability for thermal stresses.

\section{Conclusion}

In summary, we successfully fabricated the positive

\section{a) Pre-polymerization and Prebaking Steps}
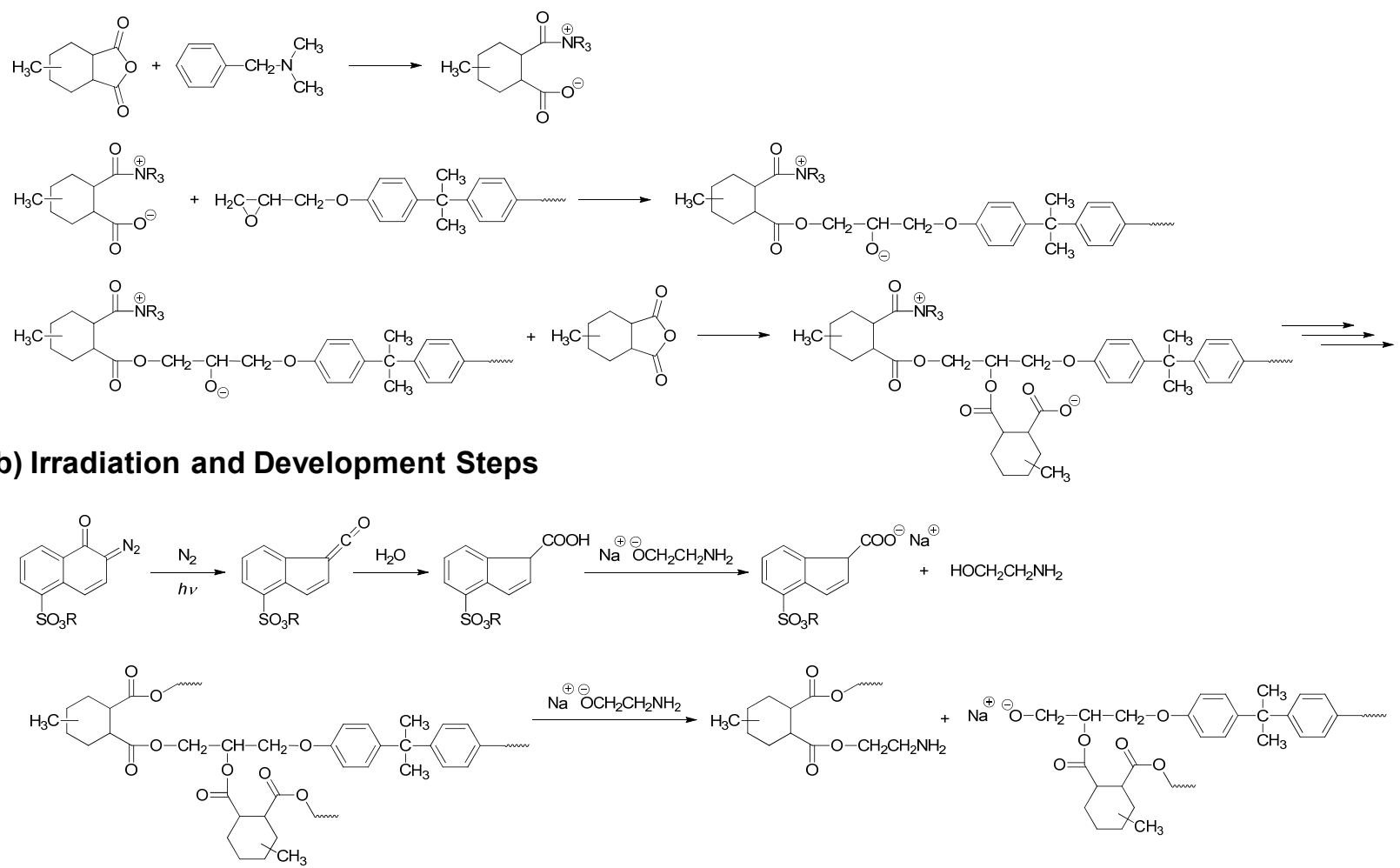

Fig. 4 Mechanisms of polymerization and pattern formation.

a) Polymerization of acid-anhydride-cured epoxy resins in the presence of tertiary amine as an accelerator.

b) RDP-based pattern formation of epoxy / DNQ systems using sodium 2-aminoethoxide as a nucleophile in developer. 
photosensitive epoxy resins based on the RDP by using B-staged polymers prepared by mixing and prebaking processes. The epoxy fine patterns were clearly formed in the development process using the developer of $15-\mathrm{mol} \%$ sodium 2-aminoethoxide in ethanolamine / NMP mixtures. To increase the feasibility and reliability of the photosensitive epoxy resins for practical uses in microelectronic industry, we will further investigate the optimum lithographic conditions and compositions of the photosensitive epoxy resins. Examinations to form finer patterns than those obtained in this study will also be carried out in our future studies.

\section{References}

1. S. Akimoto, D. Kata, M. Jikei, M. Kakimoto, High Perform. Polym., 12 (2000) 185.

2. S. -W. Park, K. Arimitsu, S. Lee, K. Ichimura, Chem. Lett., 29 (2000) 1036.

3. S. Inoue, K. Arimitsu, Y. Abe, K. Ichimura, Chem. Lett., 36 (2007) 1308.

4. N. Felix, C. K. Ober, Chem. Mater, 20 (2008) 2932.

5. I. Leonid, D. Stefan, J. Am. Chem. Soc., 131 (2009) 13315.

6. M. Miyasaka, A. Higurashi, A. Kameyama, Chem. Lett., 40 (2011) 1363.

7. J. X. Yu, Na. Xu, Z. P. Liu, L. Y. Wang, ACS Appl. Mater. Interfaces, 4 (2012) 2591.

8. Y. Kumaresan, A. Rammohan, P. K. Dwivedi, A. Sharma, ACS Appl. Mater. Interfaces, 5 (2013) 7094.

9. a) T. Fukushima, T. Oyama, T. Iijima, M. Tomoi, H. Itatani, J. Polym. Sci. Part A: Polym. Chem., 39 (2001) 3451. b) T. Oyama, J. Synth. Org. Chem., Jpn., 68 (2010) 802. c) T. Oyama, A. Kitamura, T.
Fukushima, T. Iijima, M. Tomoi, Macromol. Rapid Commun., 23 (2002) 104. d) T. Fukushima, K. Hosokawa, T. Oyama, T. Iijima, M. Tomoi, H. Itatani, J. Polym. Sci. Part A: Polym. Chem., 39 (2001) 934. e) X. Cheng, A. Takahashi, T. Oyama. Polym. J., 42 (2010) 86. f) T. Oyama, Y. Kawakami, T. Fukushima, T. Iijima, M. Tomoi, Polym. Bull., 47 (2001) 175. g) T. Miyagawa, T. Fukushima, T. Oyama, T. Iijima, M. Tomoi, J. Polym. Sci. Part A: Polym. Chem., 41 (2003) 861 (2003). h) T. Oyama, S. Senoo, M. Tomoi, A. Takahashi, J. Photopolym. Sci. Technol., 24 (2011) 523. i) T. Kawada, A. Takahashi, T. Oyama, J. Photopolym. Sci. Technol., 27 (2014) 219. j) M. Yasuda, A. Takahashi, T. Oyama, J. Photopolym. Sci. Technol., 26 (2013) 357. k) S. Yasuda, A. Takahashi, T. Oyama, S. Yamao, $J$. Photopolym. Sci. Technol., 23 (2010) 511. 1) T. Oyama, S. Sugawara, Y. Shimizu, X. Cheng, M. Tomoi, A. Takahashi, J. Photopolym. Sci. Technol., 22 (2009) 597. m) S. Sugawara, M. Tomoi, T. Oyama, Polym. J., 39 (2007) 129. o) T. Oyama, A. Kitamura, E. Sato, M. Tomoi, J. Polym. Sci. Part A: Polym. Chem., 44 (2006) 2694.

10. a) F. J. Allen, W. M. Hunter, J. Appl. Chem., 7 (1957) 86. b) Y. Tanaka, M. Tomoi, H. Kakiuch, $J$. Macromol. Sci. A-1, 3 (1967) 471. c) I. T. Smith, Polymer, 2 (1961) 95. d) H. Kishi, Y. Akamatsu, M. Noguchi, A. Fujita, S. Matsuda, H. Nishida, J. Appl. Polym. Sci., 120 (2011) 745. f) M. Tomoi, J. Network Polym., Jpn., 20 (1999) 97.

11. a) Y. Chao, Z. G. Yang, J. Appl. Polym. Sci., 129 (2013) 187. b) A. Campo, C. Greiner, J. Micromech. Microeng., 17 (2007) R81. 